\title{
Innovations in Construction Personnel Education
}

\author{
Aleksander Nicał ${ }^{1, *}$, Paweł Nowak $^{1}$, and Jerzy Rosłon ${ }^{1}$ \\ ${ }^{1}$ Civil Engineering Faculty Warsaw University of Technology, Armii Ludowej 16, 00-637 Warsaw, \\ Poland
}

\begin{abstract}
The Erasmus + programme, financed by the European Union, encourages international projects focused on education and recognition of professional qualifications. Projects presented in this paper deepen the ideas of Directive $89 / 48 / \mathrm{EWG}$, which will lead to the creation of a proper European system of comparison, certification and mutual recognition of qualifications in construction. Results of the projects will improve didactic process and qualifications recognition of European Union managers in construction. Paper presents 3 Erasmus ${ }^{+}$projects: "The Augmented Reality Formwork Assembly Training" (Project number 2016-1-PL01-KA202026102), "Common Learning Outcomes for Construction Managers in EU, part IV" (Project number 2015-1-PL01-KA202-016454), and "Continuing V.E.T. Training Programme in Lean Construction to support the transition of the Construction Sector towards a more competitive and productive model" (Project number 2016-1-ES01-KA202-025694).
\end{abstract}

\section{Introduction}

Projects, within "Erasmus +" European Union's Programme, are expected to enhance modernisation and reinforce education and training systems in response to the main challenges of today's world (employment, economic stability and growth, as well as active participation in democratic life and free labour market) [1]. According to European Commission: "The construction industry is very important to the EU economy. The sector provides 20 million direct jobs and contributes to about $10 \%$ of the EU's GDP. It also creates new jobs, drives economic growth, and provides solutions for societal, climate and energy challenges. The goal of the European Commission is to help the sector become more competitive, resource efficient and sustainable" [2]. Commission also lists the main challenges facing construction. Two of these challenges are:

- training: improving specialised training and making the sector more attractive, in particular for blue-collar workers, technical colleges and universities.

- innovation: more active uptake of new technologies.

Paper presents three Erasmus+ projects: "The Augmented Reality Formwork Assembly Training" (Project number 2016-1-PL01-KA202-026102), "Common Learning Outcomes for Construction Managers in EU, part IV" (Project number 2015-1-PL01-KA202-016454),

* Corresponding author: a.nical@il.pw.edu.pl 
and "Continuing V.E.T. Training Programme in Lean Construction to support the transition of the Construction Sector towards a more competitive and productive model" (Project number 2016-1-ES01-KA202-025694)

\section{ARFAT - Augmented Reality Formwork Assembly Training}

Developed training systems, based on modern IT technology - Augmented Reality (AR), are being constantly improved by most influential companies all over the world. Being used, among others, in trainings for pilots, F1 drivers and military personnel, it is safe to say, that AR is the future of high-quality work-based VET [3]. "The Augmented Reality Formwork Assembly Training" (Project number 2016-1-PL01-KA202-026102) deals with AR (figure 1) and another important issue - Health \& Safety.
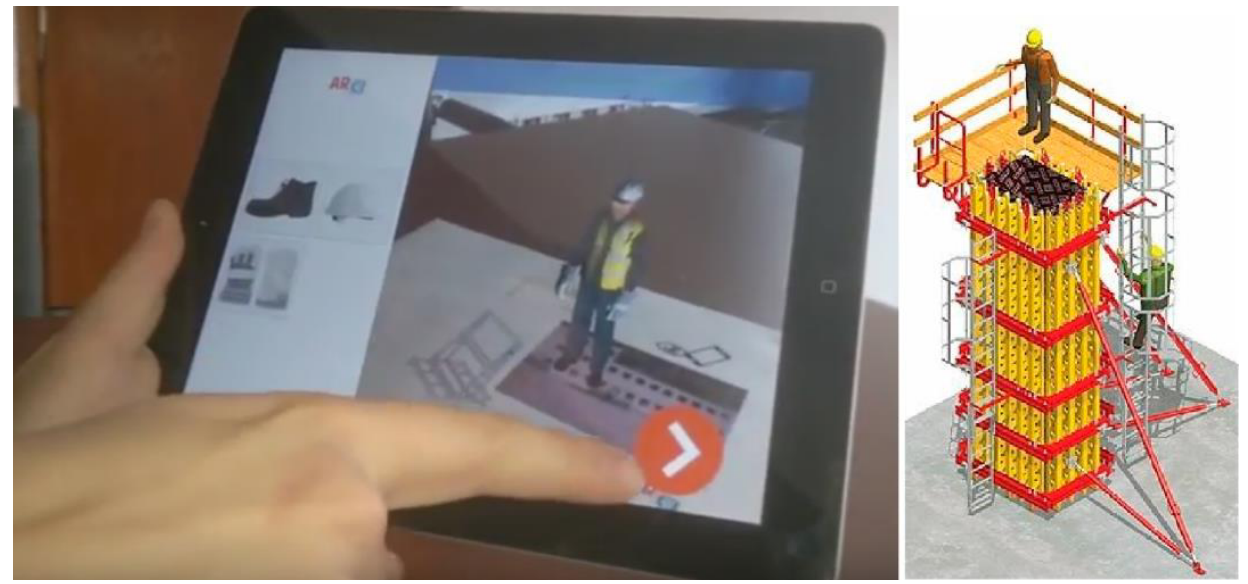

Fig. 1. AR system for formworks (source: own \& PERI).

Falls from height are the most common causes of serious accidents, often fatal, not only in Poland but throughout European Union. As human life is the most important value, there is a great need of elevating H\&S level. This problem has been raised in European Directive 2001/45/EC, which obliges to take appropriate measures to improve safety and health at work [4].

The project will address H\&S issues as it stems from the need of prevention of accidents on construction sites. These accidents are mainly caused by falling from height, especially from scaffoldings. Works at heights (i.e. formworks, scaffolding works) are one of the most dangerous among construction works. One of the main reasons is: because current training methods are insufficient. As the research shows, workers are not interested in classic trainings. Use of mobile devices (smartphones, tablets), modern AR technology and supporting media files will make ARFAT training much more interesting and unforgettable. The need for the projects was also confirmed by the questionnaires and previous project (ARCW - Health and safety procedures for curtain walls with the use of Augmented Reality Technology). Both construction employees and employers stated that there is a great need for construction trainings with the use of AR [5].

As a result of the project, training system will be created together with paper manual, application for mobile devices and supporting media files. Training will be open for all interested parties, it will use innovative methods that suit in the best way modern, digital era. Never before was AR used for formwork training. Use of mobile devices and AR technology will make the training innovative and interesting to the participants. Foreseen manual, training system and augmented reality software will contain best practices from 
different European countries in the field of formworks and scaffoldings, and series of exercises for users. ARFAT can also help to improve language competences (Polish, Spanish, English and German versions of manuals, software and training will allow users to improve their language skills).

After the completion of project, ARFAT outcomes can help to develop appropriate assessment and certification methods for formwork and scaffolding workers in EU. International contents of the training prepared on the basis of experience of international Partnership will strengthen possibility of construction staff mobility across EU. It will also help them to act in the multicultural environment - relevant to the construction site and multicultural global construction companies. Project will strengthen cooperation between industry and education sector. ARFAT will promote access to and learning through Open Educational Resources (OER), as the training will be available for all interested parties on the internet and in libraries.

The project is planned to last for 24 months, starting on the 1st of December 2016 and finishing on the 30th of November 2018. The following organisations will be involved in the Project: Warsaw University of Technology (Poland) (Project's Promoter), Polish Association of Building Managers (Poland), Technische Universitat Darmstadt (Germany), Fundacion Laboral de la Construccion (Spain), Universitat de Valencia (Spain), PERI Polska Sp. z o.o. (Poland).

The outputs containing objectives $(\mathrm{O})$ of the Project are following:

- O1: Evidence based learning outcomes. This output comprises learning outcomes on formworks and scaffolding works namely statements of what learners should know, understand and be able to do upon completion of the ARFAT training, in the form of definitions of specific knowledge, skills and competences.

- O2: ARFAT training system.

- O3: ARFAT manual.

- O4: ARFAT application (software). It is foreseen to prepare two versions of application for two most common systems for mobile devices in EU: android OS and iOS.

- O5: ARFAT AR markers.

- O6: ARFAT instructional movies.

The objective of these outputs is to develop up-to-date, tailor-suited to sectoral needs, modern formworks and scaffolding works training, appropriate to be integrated into existing VET offerings or to serve European community as a stand-alone training. These outputs will address modern skills needs of construction engineers, construction workers, stakeholders and associations in the construction sector, SMEs and companies (construction sector), VET providers, and technical universities, delivering a European solid, reliable and comprehensive pedagogical tool.

\section{CLOEMC - Common Learning Outcomes for Construction Managers in EU, part IV}

Project addresses the vocational education and training sectoral priority by improvement of vocational education and training didactic materials of the construction project management and horizontal priority by facilitation of qualification recognition system for managers in construction [6].

There is a great migration of engineers, construction managers in the construction sector due to the different state of economic development of the EU countries. For this reason, it is extremely important that construction managers' qualification and skills are being recognized and certified in the same way all over EU [7]. 
The Project is complementary to previous three CLOEMC projects, where 19 manuals (the set is also known as Construction Managers' Library - shown on figure 2) in several languages were successfully created, namely:

- (CLOEMC I) - Project Management in Construction, Human Resource Management in Construction, Partnering in Construction, Business Management in Construction Enterprise, Real Estate Management, Economy and Financial Management in Construction, Construction Management;

- (CLOEMC II) - Risk Management, Process Management - Lean Construction, Computer Methods In Construction, PPP Projects in Construction, Value Management IN Construction, Construction Projects - Good Practice;

-(CLOEMC III) - Due-Diligence in Construction, Motivation and Psychology Aspects in Construction Industry, Professionalism and Ethics in Construction, Sustainability in Construction, Health and Safety in Construction, Managing Building Pathology and Maintenance.

In CLOEMC IV project the following manuals are under preparation: Revitalisation and Refurbishment in Construction, Building Information Modelling - BIM, Optimisation of Construction Processes, Diversity Management in Construction, Mechanics of Materials and Structures for Construction Managers, Corporate Social Responsibility in Construction [8], [9].

The CLOEMC IV is promoted by Warsaw University of Technology (Division of Production Engineering and Construction Management) (Poland), partners in the project are: Technische Universität Darmstadt (Germany), Reykjavik University (iceland), Polish Association of Building Managers (Poland), Chartered Institute of Building (UK), Association of Building Surveyors and Construction Experts (UK), AWBUD S.A. (Poland).

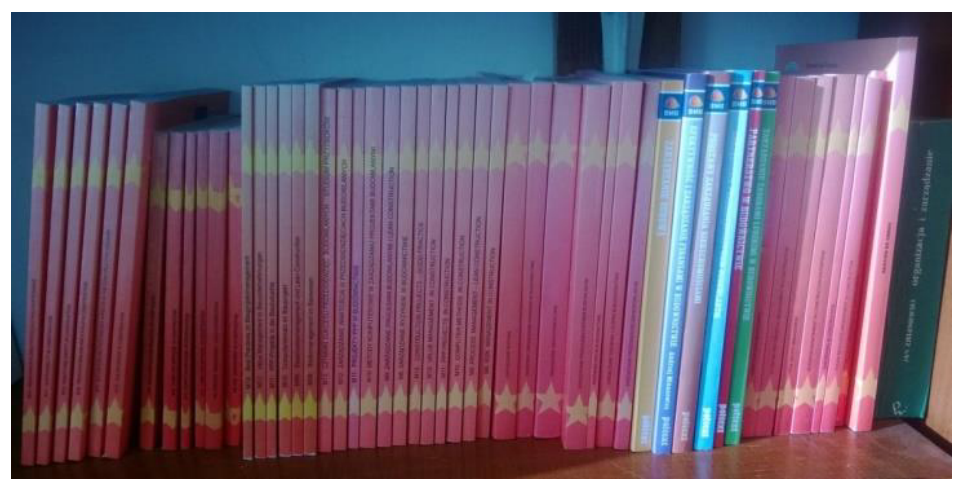

Fig. 2. Construction Managers' Library - 19 manuals printed so far (on the shelf).

In order to suit the content of the manuals to the need of construction industry, and academic and scientific needs, series of questionnaires were conducted among construction managers, civil engineering professors, and government representatives. Partial results of the questionnaires are shown in tables 1-3 and figures 3-5.

Table 1. Is the presented scope of knowledge important for Building Managers for qualifications recognition? (1 - not important; 5 - very important).

\begin{tabular}{|l|l|l|l|l|l|l|}
\hline $\mathbf{1}$ & $\mathbf{2}$ & $\mathbf{3}$ & $\mathbf{4}$ & $\mathbf{5}$ & Number of observations & Average \\
\hline 1 & 0 & 7 & 29 & 21 & 58 & 4.19 \\
\hline
\end{tabular}




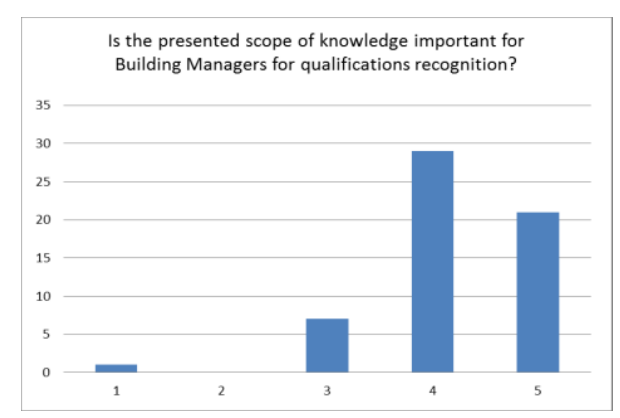

Fig. 3. Results of the survey part a.

Table 2. Are the manuals properly responding to the industry needs in respect of the managerial knowledge? (1 - not important; 5 - very important).

\begin{tabular}{|l|l|l|l|l|l|l|}
\hline $\mathbf{1}$ & $\mathbf{2}$ & $\mathbf{3}$ & $\mathbf{4}$ & $\mathbf{5}$ & Number of observations & Average \\
\hline 0 & 3 & 9 & 29 & 17 & 58 & 4.03 \\
\hline
\end{tabular}

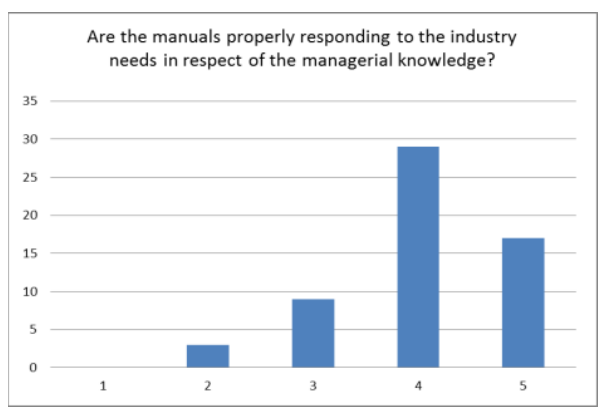

Fig. 4. Results of the survey part b.

Table 3. Will you participate (or delegate the personnel) in the Postgraduate Studies based on the created manuals? (1 - not important; 5 - very important).

\begin{tabular}{|l|l|l|l|l|l|l|}
\hline $\mathbf{1}$ & $\mathbf{2}$ & $\mathbf{3}$ & $\mathbf{4}$ & $\mathbf{5}$ & Number of observations & Average \\
\hline 6 & 4 & 18 & 12 & 14 & 54 & 3.44 \\
\hline
\end{tabular}

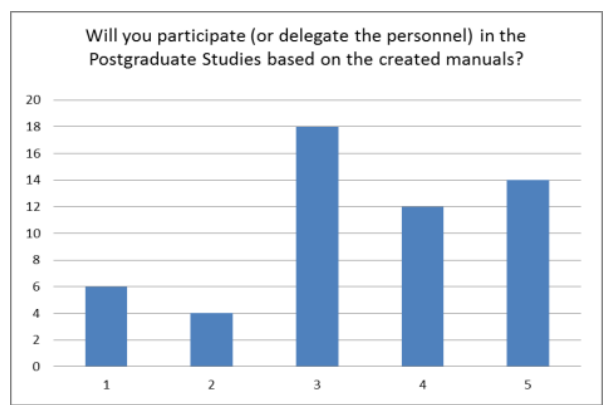

Fig. 5. Results of the survey part c. 


\section{LEANCO - Continuing V.E.T. Training Programme in Lean Construction to support the transition of the Construction Sector towards a more competitive and productive model}

LEANCO Training Programme is about training professionals from the Construction sector in Lean Construction, and bringing the necessary knowledge and competences to Professionals from the Construction sector to let them ensure the implementation of Lean Construction approach and management models within the companies of the construction sector. Figure 6 presents collectively the principles and factors decisive for success of the lean construction methodology.

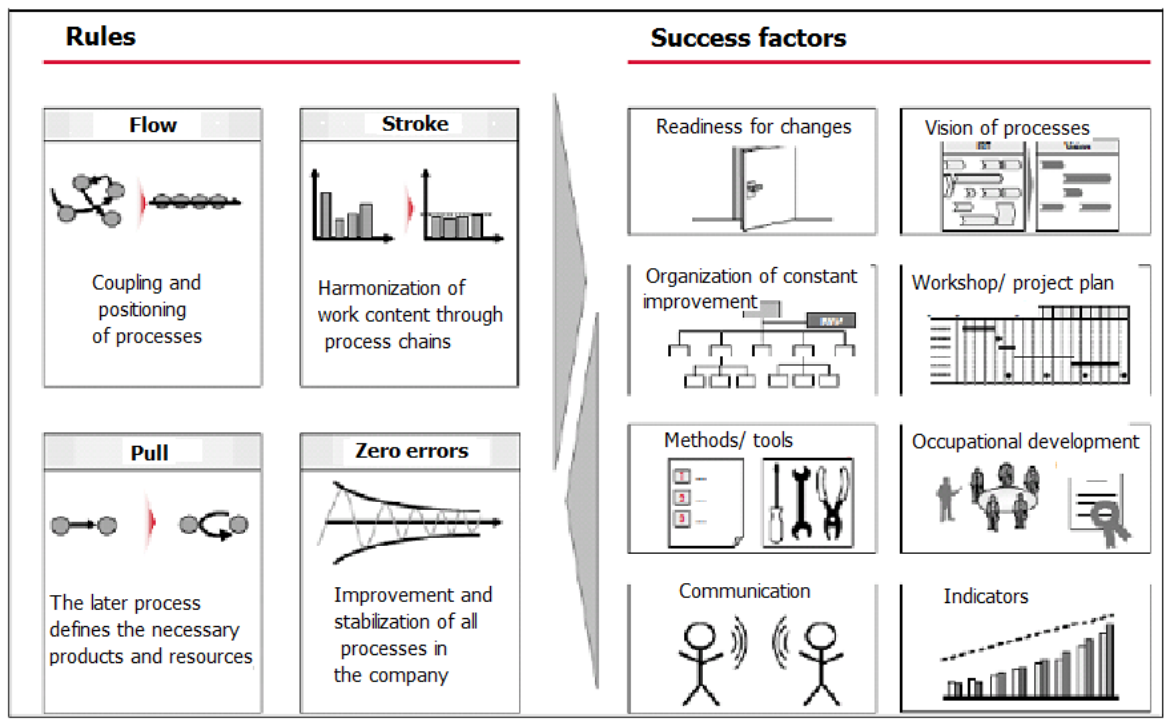

Fig. 6. Application of rules and factors that are decisive for successful implementation of lean construction [10].

The promoter of the LEANCO project is Fundacion Laboral de la Construccion (Spain), Partners are as follows: Asociación de Constructores Promotores de Navarra (Spain), ESKAL Eureka (France), Associacao Plataforma para a Construcao Sustentavel (Portugal), Civil Engineering Faculty of Warsaw University of Technology (Poland).

As a result, to reach this objective, the LEANCO Training Programme will mainly focus on mastering the principles of Lean Construction as well as its specific and related tools/methods/techniques; and on how transferring and materializing it within the companies. To do so, the LEANCO Training Programme will be made of 240 hours and will be composed of the following parts and modules:

Part 1. Conceptual Level (30 hours) aiming at providing theoretical and general knowledge about the Lean Construction in order to allow Professionals to know and understand the Lean Construction philosophy and its principles. This part will be focused on the concept of Lean Construction and its main characteristics:

- Module 1.1. Lean Principles (6 hours);

- Module 1.2. Systems Thinking (6 hours);

- Module 1.3. Lean Enterprise (6 hours);

- Module 1.4. Lean Management (6 hours);

- Module 1.5. Integration to the Construction Industry (6 hours). 
Part 2. Operative Level (160 hours) aiming at providing the specific skills to master the different tools/methods/techniques related to Lean Construction in order to allow Professionals to apply and implement the principles and practices of the Lean Construction approach within companies of the construction sector. This part will be concentrated on the main tools/methods/techniques related to Lean Construction and will be composed of the following modules:

- Module 2.1. Integrated Project Delivery - IPD (30 hours);

- Module 2.2. Value Stream Mapping - VSM (20 hours);

- Module 2.3. Building Information Modeling - BIM (60 hours);

- Module 2.4. Last Planner Simulation - LPS (50 hours).

Part 3. Transversal Level (30 hours) aiming at providing complementary training to broad and enhance competences and skills of Professionals:

- Module 3.1 Transversal issues (e.g. Kaizen Lean, 5S, etc.) (30 hours).

Part 4. Implementation LEVEL (20 hours) aiming at providing Professionals with methodology to let them transferring and implementing Lean Construction in the context of their companies:

- Module 4.1 Methodology development for Implementation (20 hours).

Regarding the methodology, the LEANCO Training Programme - a theoreticalpractical training - will be implemented through a mixed format (classroom-based and elearning sessions), with at least one classroom-based session per module. The classroombased sessions will be based on a practical methodology - workshops (simulations with models, legos and group dynamics), in a way that key concepts will be learnt through instruction, discussion, simulation and collaborative learning [11]. The e-learning sessions will also be based on a practical methodology with projects and case studies that will allow Professionals to learn training contents in an integrated way [12]. Moreover, the LEANCO Training Programme will be sustained by a didactical support all along the learning phase: the LEANCO Platform. The LEANCO Platform will be a specific tool that will act as a methodological instrument to support the LEANCO Training Programme, and as an informative and networking area in the field of Lean Construction. Thanks to the LEANCO Platform, all Professionals participating to the LEANCO Training Programme will have access to the following elements:

- consultation and exchange forums;

- e-mailing and tutorials with trainers;

- chat;

- documentation: programs, contents, learning materials and additional documents;

- directs and records of the classroom-based sessions;

- news in Lean Construction (e.g. conferences, technical seminars, press releases, etc.).

The LEANCO Platform will be developed using Blackboard tool which offers the possibility to build an intuitive, user-friendly and customizable platform, to create dynamic online trainings and to give private access to users.

\section{Summary}

The main effect of presented projects is the recognition of needs for qualifications of construction personnel, recognition of applied systems of education, certification of the personnel and accreditation of studies and courses (formal and informal) in European Union. Projects aim to develop European system, which would assure standardization of levels and transparency of construction personnel qualifications. ERASMUS+ projects are proper tools for creation of the vocational courses for all professions, including construction. The innovative aspects of the projects is that: ARFAT application will be available for mobile devices such as tablets and smartphones (Android and IOS systems); 
CLOEMC IV manuals will be used for the development of postgraduate studies in construction; LEANCO training will be available on Blackboard platform. All the described projects will significantly facilitate education process in construction sector.

\section{References}

1. A. Nicał, J. Sobieraj, Oficyna Wydawnicza Politechniki Warszawskiej, 134-141 (2013)

2. M. Książek, A. Nicał, P. Nowak, J. Rosłon, Materiały budowlane 6, 176-177 (2016)

3. A.G. Martín, A. Minasowicz, F.H. García, J.G. López, J. Rosłon, M.F. Marín, M. Książek, P. Nowak, INTED2015 Proceedings, 2124-2134 (2015)

4. M. Książek, P. Nowak, J. Rosłon, Logistyka, 6 (2014)

5. M. V. Książek, P. Nowak, J. Rosłon, Materiały Budowlane, 12 (2015)

6. P. Nowak, J. Rosłon, Technika Transportu Szynowego - koleje, tramwaje, metro, TTS 10, 471-477, (2013)

7. A. Minasowicz, P. Nowak, J. Rosłon, Proceedings 27th IPMA World Congress, Croatian Association for Project Management, 116-131 (2013)

8. A. P. Minasowicz, P. O. Nowak, J. J. Zawistowski, I-ESA 2012, Interoperability for Enterprise Systems and Applications "Shaping Enterprise Interoperability in Future Internet", conference proceedings published: M. Zelm, R. Sanchis, R. Poler, G. Doumeingts: "Enterprise Interoperability", Wiley, UK, pages. 331-338, (2012)

9. A. Minasowicz, J. Kulejewski, A. Foremny, P. Kluczuk, A. Nicał, International Conference Creative Construction, 432-441 (2012)

10. J. Kaiser: Lean Construction. In: 18. Kasseler-Darmstädter Baubetriebsseminar, Kassel (2008)

11. M. Książek, P. Nowak, J. Rosłon, Logistyka (2015)

12. A. Minasowicz, P. Nowak, E. Pellicer, J.C. Teixeira, INTED2014 Proceedings, 26392646 (2014) 